\title{
Analysis of the factors influencing information transmission at the
} calyx of Held

\author{
Zhijun Yang1, Matthias H Hennig², Michael Postlethwaite ${ }^{3}$, Ian D Forsythe ${ }^{3,4}$ \\ and Bruce P Graham*1
}

\author{
Address: ${ }^{1}$ Dept. of Computer Science and Math., Stirling University, Stirling FK9 4LA, UK, ${ }^{2}$ School of Informatics, Edinburgh University, \\ Edinburgh EH1 2QL, UK, ${ }^{3}$ Cell Physiology \& Pharmacology, Leicester University, Leicester LE1 9HN, UK and ${ }^{4}$ MRC Toxicology Unit, Leicester \\ University, LE1 9HN, UK \\ Email: Bruce P Graham* - b.graham@cs.stir.ac.uk \\ * Corresponding author
}

from Sixteenth Annual Computational Neuroscience Meeting: CNS*2007

Toronto, Canada. 7-12 July 2007

Published: 6 July 2007

BMC Neuroscience 2007, 8(Suppl 2):PI60 doi:I0.1 I86/I47I-2202-8-S2-PI60

(c) 2007 Yang et al; licensee BioMed Central Ltd.

The calyx of Held is a giant glutamatergic synapse located in the medial nucleus of the trapezoid body (MNTB) of the mammalian auditory brainstem. It is an important model system for studying short-term plasticity because each postsynaptic MNTB neuron receives only one giant synapse, and it is possible to record both pre- and postsynaptic events simultaneously. Physiological experiments show that the evoked excitatory postsynaptic current (EPSC) from the calyx displays a significant depression in response amplitude during a sustained stimulus train [1]. This observation is the result of interactions between various pre- and postsynaptic components occurring across multiple time-scales. Hundreds of readily releasable vesicles (RRVP) aggregate at the different active zones on the presynaptic terminal. The stochastic release of neurotransmitter from the RRVPs (triggered by influx of calcium ions during action potentials, APs), can exhaust the supply of vesicles. Simultaneously, the depleted RRVPs are constantly replenished by a large vesicle reserve pool, and this replenishment is also enhanced by a calcium-dependent process (mediated by the presynaptic APs). The amplitude of the presynaptic AP-evoked calcium ion concentration is affected by inactivation and facilitation of voltage-gated calcium channels as well as activation of presynaptic metabotropic glutamate receptors (mGluRs).
In this study we extend our deterministic, multiple timescale model of the calyx of Held $[2,3]$ to a stochastic version. We use information theory to measure the amount of information transmitted between pre- and postsynaptic compartments [4]. A series of long, homogeneous Poisson spike trains with mean frequencies up to several hundred Hertz are used to stimulate the calyx model. This spike train is repeated many times, allowing the calculation of the conditional and unconditional entropy of the postsynaptic EPSC amplitude in response to presynaptic interspike intervals (ISI). The mutual information, a measure of the information content of the postsynaptic response (EPSC) about the afferent spike train (ISI), is then computed in terms of conditional and unconditional entropies.

The results show that the information content in the postsynaptic response is influenced by the degree of variation of presynaptic calcium ion concentration. Rapid onset and recovery from facilitation maintains high information transfer rates across the frequency range. Suppression of calcium transients by slowly recovering inactivation and mGluR activation results in less information transmission, but prevents depletion of the RRVPs. Fast-acting postsynaptic receptor desensitisation also contributes to information transmission, but in a competitive way to facilitation. 


\section{Acknowledgements}

This work is funded by a BBSRC joint research grant (BPG \& IDF) and the MRC (IDF).

\section{References}

I. Schneggenburger R, Forsythe ID: The calyx of Held. Cell Tissue Res 2006, 326:3 II-337.

2. Graham BP, Wong AYC, Forsythe ID: A multi-component model of depression at the calyx of Held. Neurocomputing 2004, 5860:449-454.

3. Hennig MH, Postlethwaite M, Forsythe ID, Graham BP: A biophysical model of short-term plasticity at the calyx of Held. Neurocomputing 2007, 70:1626-1629.

4. Zador A: Impact of synaptic unreliability on the information transmitted by spiking neurons. I Neurophysiol 1998, 79:1219-1229.

Publish with Bio Med Central and every scientist can read your work free of charge

"BioMed Central will be the most significant development for disseminating the results of biomedical research in our lifetime. "

Sir Paul Nurse, Cancer Research UK

Your research papers will be:

- available free of charge to the entire biomedical community

- peer reviewed and published immediately upon acceptance

- cited in PubMed and archived on PubMed Central

- yours - you keep the copyright

Submit your manuscript here:

http://www.biomedcentral.com/info/publishing_adv.asp 